\title{
The African Standby Force: An Element of Prospective Multilevel Security Governance
}

\author{
Olaf Bachmann
}

Abstract This article examines the African Standby Force (ASF), an African-led mechanism for crisis management and peace consolidation in Africa, and its potential contribution to multilayered security governance. It analyses the ASF project, which has gone through many phases of redefinition since it was conceived in the late 1990s and elaborates on the inability of African stakeholders to settle on a clear concept, setting themselves ever more ambitious goals. International partners simultaneously suffer from, and contribute to, this state of affairs as their support too often responds to national or institutional interests. The ASF is also burdened by the lack of ownership by African countries and institutions. Only if $\mathrm{AU}$ member states make a conscious effort to increase their political, conceptual and especially, financial, stake in the ASF will they be able to credibly demonstrate that it is not an entirely foreign-mastered project, but a real 'African solution to African problems'.

\begin{abstract}
1 Introduction
External donors have invested a great deal in the African Peace and Security Architecture (APSA) in efforts to make it a viable multilateral instrument. Significant questions remain, however: is APSA meant to create and refine additional levels of governance? If so, how will the different levels effectively connect with one another? What would it take for its core element, the African Standby Force (ASF), to become an effective element of multilayered security governance in Africa? What would the roles of the various stakeholders be, including the UN, the African Union (AU), Regional Economic Communities (RECs), member states and international partners?
\end{abstract}

\section{The ASF: a regional security strategy tool} The ASF was envisioned by African Chiefs of Defence as early as the late 1990s, but only found its true political impetus in the African Union's Constitutive Act (2000). Articles $4 \mathrm{~h}$ and $4 \mathrm{j}$ of the Act gave the new Union the right to intervene in a member state in grave circumstances, namely war crimes, genocide and crimes against humanity (African Union 2000).

The first step in operationalising the ASF after the creation of the AU was the adoption of the
'Protocol Relating to the Establishment of the Peace and Security Council of the African Union' (PSC Protocol), in July 2002. With that Protocol, Africa endowed itself with 'a standing decisionmaking organ for the prevention, management and resolution of conflicts' (Article 2.1, African Union 2002: 4). The PSC, a council of 15 periodically elected member states is one core aspect of the APSA. It is meant to be supported by the AU Commission, a Panel of the Wise, a Continental Early Warning System, a Special Fund, and the ASF (Article 2.2, African Union 2002: 5).

The ASF is meant to be composed of five Regional Standby Force brigades from African REGs: the Southern African Development Community (SADC), the Economic Community of West African States (ECOWAS) and the Economic Community of Central African States (ECCAS), as well as two 'so-called' Regional Mechanisms (RMs) for East and North Africa respectively. It was supposed to be operational by 2010. This was not achieved for several reasons, most of which were related to a lack of capacity within the AU and the RECis (African Union 2005, 2003).

The ASF was initially conceptualised as a quick reaction force that would enable Africans to

IDS Bulletin Volume 43 Number 4 July 2012 (c) 2012 The Author. IDS Bulletin (c) 2012 Institute of Development Studies Published by Blackwell Publishing Ltd, 9600 Garsington Road, Oxford OX4 2DQ, UK and 350 Main Street, Malden, MA 02148, USA 
respond swiftly to a crisis unhampered by the heavy political and institutional burdens typical of the UN (the UN would, however, take over after an agreed period, and assume the tasks of stabilisation and peace consolidation). The concept was later refined and broken down into six scenarios: (1) observation and monitoring missions; (2) preventive deployments in the case of rising political tensions; (3) humanitarian assistance missions; (4) traditional peacekeeping operations; (5) peace support in a non-permissive environment; and (6) forceful intervention in a member state in grave circumstances.

While it constitutes a far-reaching achievement on paper, inconsistent interpretations of what the ASF should be has made its implementation difficult.

\section{The ASF: a moving target}

Early on, it was proposed that ASF brigades would be multidimensional, and would include military, police and civilian components. In practice, however, the first ASF Implementation Roadmap, which spelled out the ASF's stages of development up to 2010, reflected a strong military slant (African Union 2005). This is unsurprising given that it was worked out mainly by the military establishments of the member states and supported mainly by international partners' military establishments.

The civilian component of the ASF suffers from the resulting lack of attention, particularly with regard to training. This may be because the civilian component, with its security sector reform (SSR) experts, election support, administrative training, justice sector reform, support for parliamentary work, and so on, has the potential to play a political role and ultimately might challenge African leaders' foundations of power (i.e. challenge the status quo).

While the AU has gained field experience in the field of peacekeeping (such as the African Union Mission in Sudan (AMIS), its first field mission), the ASF has yet to be fully operationalised. With ever-more diversified partners gaining interest, and as recent UN experiences (such as with the UN Mission in the DRC (MONUG) or now the UN Stabilisation Mission in the DRG (MONUSCO)) demonstrate the increasing relevance of multidimensional operations, the need to rebalance the original concept has become increasingly obvious. To this end, a second Roadmap, adopted in July 2008, mandated accelerated work on the civilian and police dimensions of the ASF (it was already clear by then that the full operationalisation of the ASF by 2010, as foreseen in Roadmap I, could not be achieved).

\section{Roadmap II (African Union 2008) further} identified considerable tasks to be accomplished over the next two years, including work on headquarter capacity both within the AU and in the regions; decision-making and mandate issues; logistics depots; strategic lift; the rapid deployment capacity (RDG); and a variety of specific but nonetheless important domains such as medical and legal issues (African Union 2008).

In October 2010 a major mapping exercise, Amani Africa, was undertaken. Originally planned to be the final certifying procedure of the ASF and financed by European and Canadian partners, the exercise concluded that AU field operations such as AMIS and the African Union Mission in Burundi (AMIB) had demonstrated that African missions remain heavily dependent on external support for the entire range of their logistical needs, from strategic deployment to field logistics, as well as for their communications and information systems needs. Further, a situation of quasi-total financial dependence on external donors also characterises African capacity-building efforts (African Union 2010).

A new plan, Roadmap III - which, to some extent, encompasses the lessons learned from Amani Africa - was endorsed by the African Chiefs of Defence Staff in late October 2011 (African Union 2011). It recognises the lack of institutional capacity and effective coordination between the AU and RECs/RMs as one of the main blockages to standardised planning and management procedures for future ASF missions. ${ }^{1}$

This Roadmap includes ambitious additional targets, such as achieving two independent, multidimensional RDC units of 2,500 men/women each on readiness at any given time by 2012 , and full operationality of the entire ASF by 2015 (African Union 2010). The RDC, which now tops the list of priorities, combines quick reaction and multidimensionality, blurring the picture further and setting the target even higher. ${ }^{2}$ 
Currently, there is no mention of what will follow such AU RDC units, which would only be equipped for 30 days in the field. Clearly AU's hope is that once a quick response has been launched, the UN can be politically bribed into agreeing to send in UN forces with UN funding. This may work with hybrid AU-UN operations, which are difficult enough to establish. The case of the African Union Mission in Somalia (AMISOM), however, is a good example that this calculation is flawed (Le Gouriellec 2012).

Adding to the level of complexity, other new tasks have appeared on the list of possible ASF commitments in addition to the RDC, including disaster relief and naval operations. It is clear from recent conceptual work and ongoing operations that the AU's and RECs' aims are now pitched at the upper end of the scale of scenarios developed in the original Roadmap. An escalating trend is visible in three directions:

- from a 'fire brigade' type of operation, carried out by an agile, relatively unsophisticated ASF (who subsequently hand over operations to the UN), to a scenario where Africans themselves assume peace consolidation tasks in the long run;

- from mainly military-focused missions, to multidimensional operations, additionally endowed with the whole range of civilian and police components; and

- from low-risk deployments in relatively peaceful contexts, to operations in environments with a high level of 'spoilers'.

No open debate has been carried out on those evolving assumptions, their political underpinnings or feasibility requirements. Built on unaddressed issues and high expectations, the ASF is therefore a moving target, due to the inability of African stakeholders to settle on a clear concept, setting themselves ever more ambitious goals at every stage.

\subsection{Shared responsibility and regional ownership of the process}

Although there are a number of bilateral and multinational contributors to the ASF, the European Union (EU) has carried the lion's share of support for developing the ASF since 2007. Of course, the UN's involvement, and G8 support need to be acknowledged but the EU, particularly, demonstrates the main difficulties, in terms of ownership, that need to be addressed.

The political instrument for helping Africans to help themselves was set up as the African Peace Facility (APF), which was drawn from the 9 th European Development Fund (EDF). Originally budgeted at $€ 300$ million, most of the money was quickly spent on Peace Support Operations in the Comoros, Sudan, Somalia, and the Central African Republic. The APF was then expanded to $€ 440$ million. However, only one third of the €35 million that was reserved for capacity-building measures and strengthening institutions had been used by 2010 (interview, ECCAS technical assistant, Libreville, December 2010). In fact, the AU and the RECs are not able to absorb all the money on offer from different - especially bilaterally competing - donors, who are queuing up to spend their Overseas Development Assistance (ODA) in Africa (APF funding under the 9th EDF did not count against their ODA). The next African Peace Facility of the 10th EDF is already decided upon with a budget of $€ 600$ million, of which $€ 65$ million is dedicated to capacity-building (European Commission 2012).

One of the 'flagships' of EU support to capacitybuilding was supposed to be Peacekeeping Training Centres (PTCs) for the ASF. However, this project has been repeatedly delayed by misunderstandings between European and African partners, and among different parts of the EU bureaucracy, poor expertise, and disregard for the partners' views. For instance, in the spring of 2009, a joint EU-AU delegation was scheduled to undertake an initial assessment of the PTC to finally decide which Training Centres would get what funding. However, the AU delegates never showed up. Officially the AU had not been able to obtain visas for its delegates. The reality, however, was that the EU had pressed on the earliest possible date to commence, although the AU had signalled that they were not yet ready (separate interviews with $\mathrm{AU}$ and EU officials, December 2010).

It is extremely difficult to assess the effectiveness of multilevel donor support, as there are no clear benchmarks, or the hierarchy among those benchmarks is debatable. Multiple strategic partnership communication exists between individual African and European states, and at least, on the European side, at sub-state level. 
At times, it appears that Western states overdo the variety of their contacts with the AU and African regions at the expense of efficiency. For instance, in Spain, autonomous regions develop their own Africa policies, and in Germany four different ministries have their own independent Africa policy projects, which sometimes - but not necessarily - dovetail with each other or with policies decided on at EU level. The resulting confusion between European and African partners has rarely been subject to discussion. Each side consists of quite differentiated political bodies, both formal and informal, which are interpreted by each actor involved according to his politico-cultural awareness and preferences.

The lack of clarity in assumptions largely explains the discrepancies and lack of coherence in donor support. As long as all assumptions remain potentially valid, and none has clear authority over the others, each donor remains free to 'pick and choose' among the components of the ASF that best match its national preferences or habits. For instance, French and American interests are in the tactical military fields, the French are much invested in tactical and operational military formation, and Germany, Canada, and Italy concentrate on police training - each of them in countries, or with organisations, of their immediate interest and choice.

It must be said that African partners, too, pick and choose from what is on offer. As mentioned earlier, whilst the initial APF €265 million funding for operations, salaries, and equipment had to be extended by an additional €140 million, the €35 million for capacity training was only reluctantly called on. The USA's and French bilateral support to Africa are much more popular with recipients, because they often mean material support to the military.

Generally, demand for improving the professional capacities of staff and personnel other than military is limited. In ECCAS two thirds of the jobs that could advance regional integration and administrative performance are empty, although full funding for salaries is provided. (Sub-)regional organisations often just cannot absorb all the money on offer.

\subsection{Regionally integrated security policy: who does what and who decides what?}

It appears that the potential advantages of mutually beneficial policymaking are still hampered by difficulties of hierarchy between the different prospective layers of governance. That different layers of governance exist - or that they can be established if not - is not in doubt. But questions remain as to who has the authority to decide what at which level, and who should implement what.

The hierarchical order between the different prospective layers is not evident: theoretically, in the political sphere the UN Security Council leads, followed by the AU, the RECs and RMs, followed by the individual states, which would have to implement the formers' policy decisions. The reality is the opposite, however: the power to direct, execute and implement rests with the individual states. For example, although the Peace and Security Council of the AU was officially designed as a decision-making body, states ignore PSC decisions whenever it suits them.

To take, for example, the case of AMISOM: launched in 2007 it took four-and-a-half years before more than two member states contributed seriously to this operation, and then it was Kenya rushing headlong into a campaign to protect its international reputation as a stable state, and its tourism industry. The fact that Kenyan troops are now attached to AMISOM is largely a result of the sobering costs of a longer than expected military campaign. Generally, the AU commands little respect from its member states; an organisation that cannot even muster membership fees from the majority of its member countries (a problem it shares with the regional economic organisations) is not a powerful player to be followed in contested political cases. Whether member states will actually honour the $\mathrm{AU}$ decision to provide the troops to beef up AMISOM to up to 17,000 strength remains to be seen. Currently, a core problem for regional and sub-regional security integration is the missing political joint vision of a common strategic goal. Without the weight of member states behind them, RECs, which are supposed to implement AU decisions, will not do so.

The sub-optimal development of political means to deliver a policy according to the premises of the AU constitution is primarily caused by African states. To take one example of such existing difficulties: Angola and the Democratic Republic of Congo are members of both ECGAS and SADC. Hence, both of them participate halfheartedly in the development of two sub-regional 
ASF brigades. The recent announcement by President Déby of Chad that he wishes to join ECOWAS is another bewildering case in point, particularly because the newly chosen Secretary General of ECGAS is from Chad. Another example: the United Nations Standing Advisory Committee on Security Questions in Central Africa (UNSAC), which has met twice yearly since 1993, can be seen as being in direct competition with ECCAS. It appears as if countries do not want to decide between any of these structures. One therefore wonders whether countries' policies are truly committed to advancing regional integration via their subregional organisation. Under such conditions, projects logically lack ownership.

Regional integration can be translated into multilevel governance: there is a dialectic interaction between the two. Regional integration can spread out into, and bring into being, new levels of governance, be this in the form of confidence-building measures between states, or even as institutionalised security alliances. APSA displays many indicators of such an alliance. But for the time being, Africa remains the least integrated region of the world in many respects (although differentiations between sub-regions apply). Presently African states often remain preoccupied with their sheer survival, barricaded behind national and customs boundaries. The understanding that one's own existence can be ameliorated through the indirect approach of bettering the common neighbourhood has yet to become manifest. A means to achieve better integration would depend on the willingness to (1) pool, and (2) delegate responsibility (or, in other words, power). The implications of this are:

1 The lack of means of average contemporary states demands a build-up and pooling of capacities sufficient to address common problems. APSA would appear the best means to pool political power, and the ASF could provide it with an instrument to share the burden of keeping the peace. Unfortunately (so far) nowhere does a reliable binding legal document exist with AU or REGs member states, between member states and RECs, or the AU and member states, for the deployment of pledged troops to the ASF. This means that in fact there is no legal or other claim at any level of the APSA structure to direct ASF forces.
2 Delegating responsibility can work in manifold directions to simultaneously address firstly, the overarching tasks beyond the level of nation states - preferably in a multilateral fashion, and secondly, more specialised, or geographically limited tasks, at lower levels of governance.

If successfully implemented this accumulation of capacities on a multilateral level may constitute a shared political ownership of regional security.

\section{Conclusion}

The ASF project has gone through many phases of definition and redefinition since it was conceived in the late 1990s. This article has argued that the ASF is a 'moving target', due to the inability of African stakeholders to settle on a clear concept, setting themselves ever more ambitious goals at every stage.

Partners simultaneously suffer from, and contribute to this state of affairs. Whilst coordination efforts are undertaken, partners' support too often still responds to national or institutional interests, and each partner uses the leeway created by the conceptual ambiguities of the ASF to press its own priorities.

Also, the overwhelming role of non-African partners in the conceptual maturation of the $\mathrm{ASF}$, and the impact of their funding decisions, exacerbate the confusion about the true direction of its development. The ASF is burdened by the lack of political, conceptual, and financial ownership. The result is at best an ambiguous partnership between all stakeholders and external partners involved, and at worst a waste of human resources, financial means and political capital.

Only if AU member states make a conscious effort to increase their political, conceptual and especially, financial, stake in the ASF will they be able to credibly demonstrate that it is not an entirely European-mastered project.

This may in turn provide a real step towards common African policymaking. Multilevel governance depends on the ability and willingness to share a common vision and to pool and delegate power towards its implementation. Whilst the ability can be enhanced through external support, the willingness requires proactive ownership by member states. 
The AU Commission, representing a prospective level of multilevel governance, should work with the RECs to improve and ensure connectivity at all levels, including transfer of information from all RECs to the AU. For example, there has been a sitting ECCAS liaison representative at the AU since late 2007. Although his post is paid for by the EU he has low visibility, and he still needs ECCAS permission to travel between the seats of ECGAS and the $\mathrm{AU}$, which is not always granted (interview, ECCAS official, March 2010). It is therefore critical for the AU and RECs' member states to clarify the level and mandate of the liaison officers.

At the legal level the AU, RECs and RMs should adopt binding legal documents with member states

\section{Notes}

1 Roadmap III reads: 'The lack of institutional capacity and effective coordination between the AU and RECs/RMs is one of the main blockages to standardized planning and management procedures for future ASF missions' (African Union 2010: 50).

2 As a comparison, a purely military EU battle group, which comprises an extended battalion

\section{References}

African Union (2011) 'Workshop on the Finalization of the ASF Roadmap III', press release, Douala, Cameroon, 27-29 April

African Union (2010) PSOD Key Elements of the Policy Documents of the African Standby Force, paper prepared for the 4th Ordinary Meeting of the Specialised Technical Committee on Defence, Safety, and Security, for the preparatory meeting of the African Chiefs of Defence Staff and Heads of Security and Safety Services, Addis Ababa, 3-7 December

African Union (2008) 'The African Standby Force Roadmap II', adopted at the Consultative Meeting between the African Union Commission, the Regional Economic Communities, Regional Mechanisms and the Planning Elements of the African Standby Force (ASF) Regional Brigades, Addis Ababa, 30-31 July 2008

African Union (2005) 'Roadmap for the Operationalisation of the African Standby Force', EXP/AU-REGs/ASF/4(I), Experts' Meeting on the Relationship between the AU and the Regional Mechanisms for Conflict Prevention, Management and Resolution, Addis Ababa, 22-23 March for the deployment of pledged troops. This would emphasise reliability through institutionalisation. Also, this would clarify who can decide on the deployment of the ASF. ${ }^{3}$ As a supplementary benefit, this would mitigate cases of competition between, for instance, ECOWAS and the AU, as seen in the example of Côte d'Ivoire. ECOWAS does not appear keen on any AU involvement in an issue they - in their view - can sort out much better on their own.

Finally, decisions already made must be implemented: this includes, for instance, the offer Angola made in 2008 to send a 150-strong formed-police-unit to the Mission de consolidation de la paix en Centrafrique (the peace support operation in the Central African Republic).

of 1,500 men costs $€ 100$ million for six months of permanent readiness.

3 Roadmap III addresses this topic as follows: 'In the same vein, a comprehensive MOU on the use of the ASF for AU mandated missions, needs to be finalized and adopted. This MOU should clarify the relationship between the AU, REGs/RMs and Member States' (African Union 2010: 50).

African Union (2003) 'Policy Framework for the Establishment of the African Standby Force and Military Staff Committee, (Part 1 and 2 Annexes)', adopted by the 3rd meeting of African Chiefs of Staff, Addis Ababa, 12-14 May

African Union (2002) Protocol Relating to the Establishment of the Peace and Security Council of the African Union, adopted by the 1st Ordinary Session of the Assembly of the African Union, Durban, 9 July

African Union (2000) Constitutive Act of the African Union, OAU Assembly, Lomé, Togo, 10-12 July, entry into force 26 May 2001, www.chr.up.ac.za/ hr_docs/documents/African_Union_ Constitutive_Act.pdf (accessed 2 April 2012)

European Commission (2012) African Peace Facility, EuropeAid Development and Cooperation, http://ec.europa.eu/europeaid/where/acp/ regional-cooperation/peace/index_en.htm (accessed 2 April 2012)

Le Gouriellec, S. (2012) L'ONU en Somalie : le Refus de l'Engagement? Réseau Francophone de Recherche sur les Opérations de Paix, Université de Montréal, www.operationspaix.net/66-dossierdu-rop-lonu-en-somalie-le-refus-delengagement-.html (accessed 2 April 2012) 